Budiarti et al., Afr., J. Infect. Dis. (2018) 12(S): 1-6

https://doi.org/10.21010/Ajid.v12i1S.1

\title{
IN VITRO STUDIES ON HEME OXYGENASE-1 AND P24 ANTIGEN HIV-1 LEVEL AFTERHYPERBARIC OXYGEN TREATMENTOFHIV-1 INFECTED ON PERIPHERAL BLOOD MONONUCLEAR CELLS (PBMCS)
}

\section{Retno Budiarti $^{1 *}$, Kuntaman ${ }^{2}$, Nasronudin ${ }^{3}$, Suryokusumo $^{4}$, Siti Qamariyah Khairunisa ${ }^{5}$}

${ }^{1}$ Department of Microbiology, Faculty of Medicine, Hang Tuah University, Surabaya, Indonesia; ${ }^{2}$ Department of Microbiology, Faculty of Medicine, Airlangga University, Surabaya, Indonesia; ${ }^{3}$ Department of Internal Medicine, Faculty of Medicine, Airlangga University, Surabaya, Indonesia; ${ }^{4}$ Department of Hyperbaric, Faculty of Medicine, Pembangunan Nasional University, Jakarta, Indonesia; ${ }^{5}$ Department of HIV, Institute of Tropical Disease, Airlangga University, Surabaya, Indonesia

"Corresponding Author Email: retnobudiarti@yahoo.com

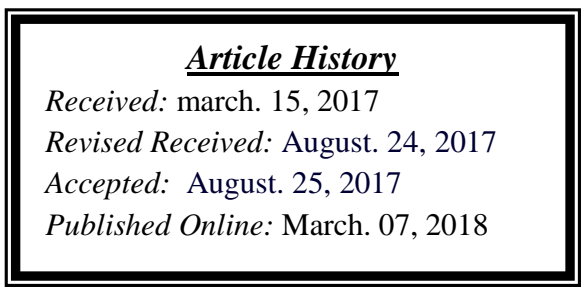

\section{Abstract}

Background: Heme oxygenase-1 (HO-1) is a protein secreted by immune cells as a part of immune response mechanism.HO-1 can be induced by variety agents that causingoxidative stress, such as exposure to $100 \%$ oxygenat 2,4 ATA pressure.It plays a vital role in maintaining cellular homeostasis. This study was conducted to identify the effect of hyperbaric oxygen exposure in cultured ofPBMCthat infected by HIV-1.

Material and Methods: Primary culture of PBMCs were isolated from 16 healthy volunteers and HIV-1 infected MT4 cell line by co-culture. The PBMCs were aliquoted into two wells as control group and treatment group. The 16 samples of HIV-1 infected PBMCwere exposed to oxygen at 2,4 ATA in animal hyperbaric chamber forthree times in 30 minutes periods with 5 minutes spacing period, that called 1 session.

The Treatment done on 5 sessions within 5 days. 16 samples of HIV-1 infected PMBCs that have no hyperbaric treatment became control group.The supernatant were measured the HO-1 production by ELISA andmRNA expression of HO-1 by real time PCR and the number ofantigen p24 HIV-1by ELISA.

Results: The result showed that there was no increasing of HO-1 at both mRNA level and protein level, there was a decreasing number of antigen p24 HIV-1 at the treatment group. In addition, hyperbaric exposure could not increase the expression of HO-1, more over the viral replication might be reduced by other mechanism.

Conclusions: Hyperbaric oxygen could increases cellular adaptive response of PBMCs infected HIV-1 through increased expression of proteins that can inhibit HIV viralreplication.

Keywords: HIV-1, hyperbaric oxygen, heme oxygenase-1 (HO-1), mRNA, qPCR.

\section{Introduction}

Hyperbaric oxygen (HBO) therapy is exposure of pure oxygen at the pressure more than 1 ATA. During therapy, the haemoglobin reaches $100 \%$ saturation and more oxygen is dissolved in the plasma than usual, and high amount of oxygen is delivered to almost all tissues, enhancing blood and tissue oxygenation (Simsek et al., 2011).

Exposure to pure oxygen in HBO therapy with therapeutic doses can increase oxidation products and the effectiveness of antioxidant defence mechanisms to prevent oxidative stress. Increased production of the superoxide radical followed by hydrogen peroxide will impactthe transcription factors with their main target protein heme oxigenase-1 (Simsek et al., 2015).Heme oxygenase-1 (HO-1) was increase 24 hours after hyperbaric oxygen exposure suggesting an involvement of HO-1 in the adaptive protection (Speit and Bonzheim, 2003). Heme oxygenase-1 is a protein which is highly inducible by a variety of agents causing oxidative stress and play a vital function in maintaining cellular homeostasis along with increase resistance against oxidant mediated cell injury. HO-1 involved in the adaptive protection against the induction of DNA damage after HBO treatment (Rothfuss et al., 2001). 
The previous study reported the role of HO-1 in monocytes against HIV infection, showed that HO-1 suppresses HIV-1 replication in primary human monocytes by PKC-dependent HO-1induction (Devadas et al., 2010). The other study showed that there was a strong evidence forHO-1 as a novel endogenous biologic component with anti HIV activity (Devadas and Dhawan, 2006). The aim of this study was to identify the effect of HBO whether HO-1 produced after hyperbaric oxygen exposure could inhibit the HIV-1 replication.

\section{Materials and Methods Design Experiment}

This study was approved by the Institutional Ethics Committees of Medical Faculty Airlangga University Surabaya, Indonesia. Informed consent was obtained from all volunteers prior to sample collection. We recruited sample from healthy volunteers purposively with criteria as follows, aged about 18-23 years old, not suffering from chronic illness, not taking drugs such as steroids, cytostatic and drugs and not smoking. Eight milliliters of whole blood were obtained from each 16 healthy volunteers who had approved informed consent.This Peripheral Blood Mononuclear Cells (PBMCs) were further isolated and divided into two groups; treatment group (with HBO) and control group (no HBO).

\section{Isolation and Preparation of PHA-stimulated uninfected volunteer Peripheral Blood Mononuclear Cells (PBMCs)}

PBMCs were separated from whole blood freshly collected by using histopaque (SIGMA) density gradient centrifugation prepared frombuffy coat. PBMCs were re-suspended in RPMI 1640 (Gibco) medium supplemented with $10 \%$ heat inactivated fetal bovine serum (FBS), $2 \mathrm{mM}$ L-glutamine, $100 \mu \mathrm{g} / \mathrm{ml}$ streptomycin, $10 \%$ purified human IL-2 (SIGMA) and10 $\mu \mathrm{g} / \mathrm{ml}$ PHA (SIGMA).The number of variable cells were counted by usingtrypan blue and hemocytometer. Viable cells looks clear, while the necrosis cells (nonviable cells) was blue. PBMCs were aliquoted into two wells of sterile 24 wells plate at concentration $5 \times 10^{5}$ cell/ $\mu$, one well for control group and one well for treatment group. The uninfected PBMCs were cultured in medium with stimulated phytohemagglutinin (PHA, 10 $\mu \mathrm{g} / \mathrm{mL}$ ) and incubated for three days in $\mathrm{CO}_{2}$ incubator. After three days, the culture fluid was incubated in RPMI-1640 medium containing $\mathrm{T}$ cell growth factor cytokine IL-2 for three days in $\mathrm{CO}_{2}$ incubator, to reach the cell concentration of PBMC up to $1 \times 10^{6}$ cell/ $\mu 1$.

\section{Infection with HIV-1}

Primary PBMCs culture fluid were infected with HIV-1 by co-cultured withHIV-1 MT4cell linein BSL-3 (Bio Safety Level 3) laboratory, Institute of Tropical Diseases (ITD) Universitas Airlangga, Surabaya, Indonesia. HIVinfected PBMCs cultures were experimental units in this study. A total of 32 PBMCs infected cultures consist of 16 samples treatment group (with HBO) and 16 samples control group (non HBO).

\section{Exposure to $\mathrm{HBO}$}

The treatment group receivedHBO exposure. HBO exposure was performed in a hyperbaric animal chamber with temperature controlled $\left(37^{\circ} \mathrm{C}\right)$. The experiment were conducted 3 times for 30 minutes, at 2,4 ATA and $\mathrm{O}_{2} 100 \%$ and did intermission in 5 minutes with $\mathrm{O}_{2} 21 \%$. HBO exposure was performed at second day post HIV-1 inoculation for 5 days. However the control group did not receive hyperbaric oxygen exposure. After the last HBO exposure, the examination was performed on both treatment group and control group, supernatant that was containing virus were harvested by centrifugation $1500 \mathrm{rpm}$ for $5 \mathrm{~min}$,and were stored at $-80{ }^{\circ} \mathrm{C}$ for examination. The supernatant was measured for the concentration of HO-1 by ELISA and mRNA expression by qPCR.

\section{Quantitative analysis of $\mathrm{HIV}-1$ replication}

The supernatant were assayed for HIV p-24 used ELISA analysis kit (RETROtex, Zeptometrix corporation buffalo, NY) according to the manufacturer instructions. Supernatant were collected to determine viral production level with measurement of HIV-1 p24 antigen.The level of captured p24 was determined by measuring the absorbance in wave length $450 \mathrm{~nm}$ using spectrophotometer. 

(qPCR)

The supernatant were assayed for HO-1 using ELISA kit (R\&D systems) and the examination levelsof HO-1 was performed according to the procedures contained on the ELISA kit.To see whether the expression of HO-1 at the gene level is different from the expression at the protein level, we performed the examination by using 2 methods, measured the HO-1 protein by ELISA and measured the expression of the gene that encoding this protein by qPCR.

RNA were extracted from cell culture using the QIA-amp RNA Mini kit (Qiagen,Hilden, Germany).RNA was reversedinto cDNA using the SuperScript III First-StandSynthesis kit (Invitrogen, Carlsbad, CA). The ssDNA concentration was determined by using Nano Drop spectrophotometer. While cDNA generation used a reverse transcriptase kit,qPCR was performed using SsoFast ${ }^{\mathrm{TM}}$ EvaGreen supermix (Bio Rad) with the primer sets.qPCRreaction was carried in a $10 \mu \mathrm{l}$ reaction mixture containing $5 \mu 1$ SsoFast ${ }^{\mathrm{TM}}$ EvaGreen supermix (Bio Rad), 1 $\mu \mathrm{l}$ each primer, $2 \mu$ ltemplate and $1 \mu 1$ nuclease free water.HO-1 gene were amplified by PCR using the following primer pairs (sense 5'-CCT GCT CAA CAT CCA GCT C-3',antisense 5'CTA CAG CAA CTG TCG CCA C- 3').mRNA levels were expressed in relative copy number normalised against GADPH mRNA.This normalisation against the housekeeping gene is possible if both PCR (HO-1 gene thousekeeping gene) present in the same efficiency.

All data are expressed as the mean value and its standard deviation. Kolmogorov smirnov to analyse the distribution, followed by dependent test to analyse statistic $(\alpha=0.05)$.

\section{Results}

\section{Level Heme Oxygenase-1 (HO-1) after hyperbaric oxygen treatment on PBMCs cultureinfected by HIV-1}

This study was performed on 32 samples of PBMC cell cultures infected with theHIV-1 MT4 virus, which is divided into 16 samples with hyperbaric oxygen treatment and16 samples as the control group. The number of cells in healthy PBMCs cultured wascalculated until $1 \times 10^{6}$ cells/ $\mu$ l and the number of HIV-1 MT4 cell line was $1 \times 10^{6}$ cells/ $\mu$ l too. The number of cells both in treatment and control group were homogeneous. The result showed that the treatment group concentrations of heme oxygenase-1 protein were slightly higher compared to the control group (Figure 1). Mean on treatment group was $1.38 \mathrm{ng} / \mathrm{ml}$, and on control group was $0.89 \mu \mathrm{g} / \mathrm{ml}$. Heme oxygenase-1 measurement was conducted 24 hours after the last of the hyperbaric oxygen exposure.

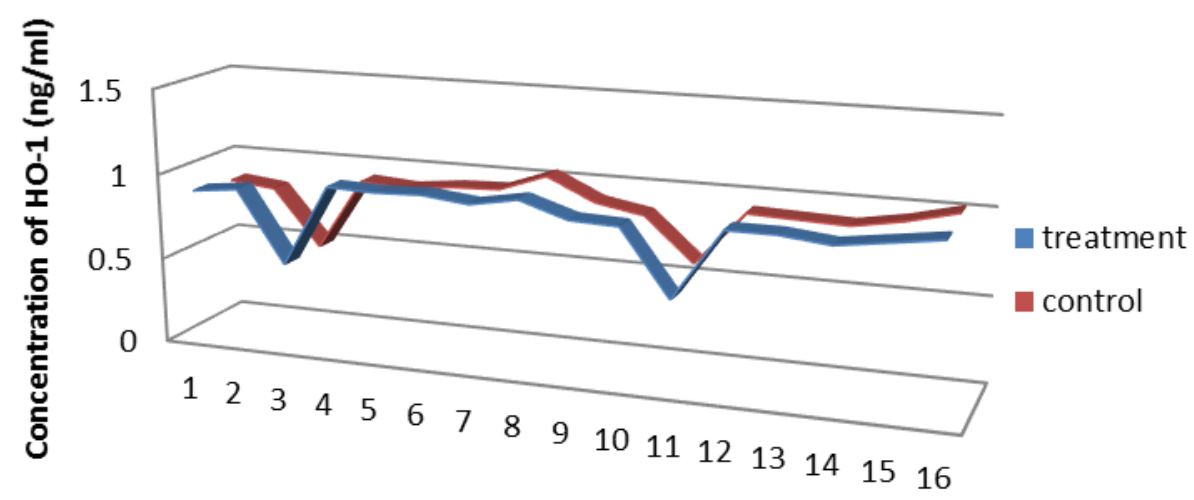

Sample

Figure 1: Concentration of HO-1 protein

Expression of Heme oxygenase-1 gene by quantitative RT-PCR obtained the following results as showed in Figure 2 


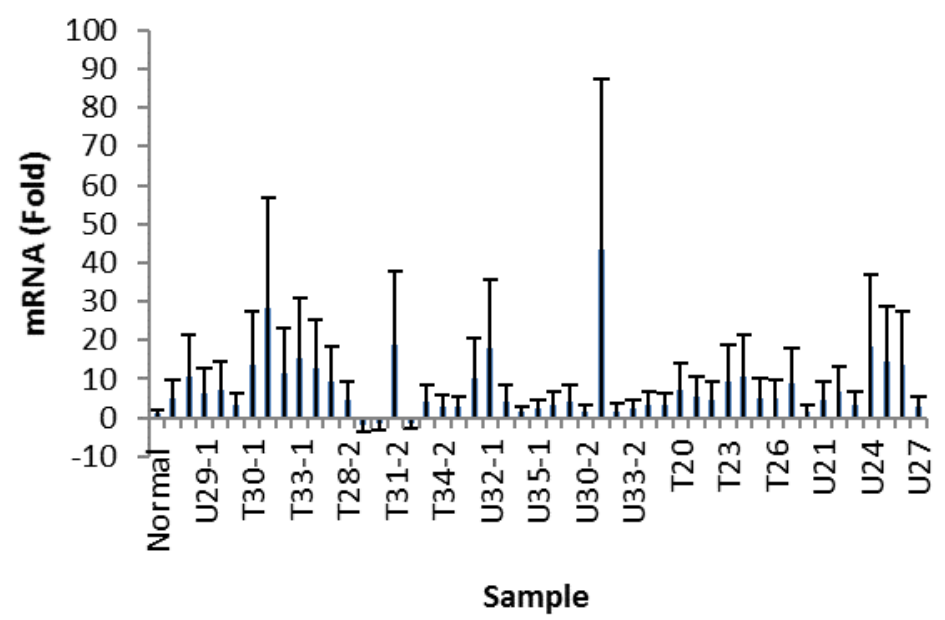

Figure 2: The mRNA expression activity of the gene encoding heme oxygenase-1 after HBO exposure

Table 1: Difference value between HO-1 and mRNA expression qPCR

\begin{tabular}{|l|c|c|c|c|}
\hline \multirow{2}{*}{ Group of treatment } & \multicolumn{2}{|c|}{ HO-1 (ng/ml) } & \multicolumn{2}{c|}{ HO-1 mRNA (fold) } \\
\cline { 2 - 5 } & Mean & SD & Mean & SD \\
\hline HBO Treatment & 1.38 & 2.04 & 30,980 & 1,40 \\
\hline No HBO Treatment & 0.99 & 0.15 & 28,526 & 1,32 \\
\hline & $\mathrm{P}=0,600$ & & $\mathrm{P}=0,056$ & \\
\hline
\end{tabular}

At the protein level, using the WilcoxonSum Rank test showed a significance level of $p=0.600(p>\alpha)$, which means there was no difference in the levels of this protein in the treatment and control groups.Although the average levels of HO-1 was higher in the treatment group comparedwith the control group, there was nodifference in protein levels of heme oxygenase-1 after exposure to hyperbaric oxygen between treatment group and control group (Table 1).

At gene expression level, Wilcoxon Sum Rank test results showed $p=0.056(p>\alpha)$. Means that therewere no significant differences in mRNA levels HO-1 between treatment group and control group.

\section{The number of virus with the HIV-1 p24 antigen}

The number of virus was measured byassessing levels of HIV-1 p24 antigen. The results showed the levels of HIV-1 p24 antigen in thetreatment group was less than in the control group.

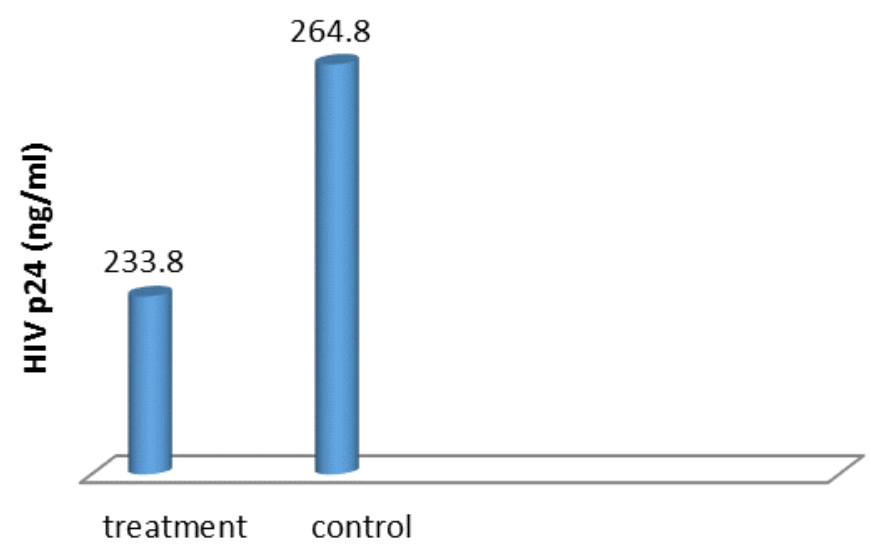

Figure 3: The average amount of HIV-1 p24 antigen (ELISA) between treatment and control group

Different test using WilcoxonSum Ranktest showed the results of $p=0.039(p<\alpha)$, which means that there was asignificant difference in the amount of p24 antigen levels of HIV-1 between treatment group and control group. 


\section{Discussion}

\section{Analysis of the expression of mRNA and protein levels of the enzyme hemeoxygenase-1}

Compared with the control group, the levels of heme oxygenase-1 protein was higher in the treatment group, evenstatisticallythere was no significant difference. However, the gene expression of heme oxygenase-1 there were no significant difference expression between treatment group and control group.HO-1 protein is a protein on group of heat shock protein that serve as protectiveprotein in cell mechanisms against stressor. The exposure of HBO on cell will impact on production of free radical that induce the expression of HO-1 gene.

In this study, the level of HO-1 protein was not increase, there was a transcriptional regulatory that affect the expression of protein HO-1 incell. In samples, with hyperbaric oxygen treatment, sources of oxidants derivedfrom viral replication and hyperbaric oxygen. On the other hand, withouthyperbaric oxygen, the oxidant source only derived from viral replication. Treatment control Hemeoxygenase protein, also known as heat shock protein (Hsp) 32 , were regulator of transcription factors by cell under stress conditions such ashypoxia, exposure to cytotoxic and hyperthermia (Abdalla et al., 2004), and also by free radical (Gill et al., 2015). The suppression of HO-1 protein levels was identified in cultured macrophagesfrom human brain tissue infected by HIV-1.The decreased in the expression of this enzymes in the macrophage cells was associated with increased oxidativestress due to viral replication and enhancement of glutamate as a result of injury tonerve tissue (Gill et al., 2015).The increase oxidants level in cells due to ongoing viral replication and the presence of reactive molecules of oxygen species (ROS) as a result of exposure to hyperbaric oxygen.

The results showed that this studywas not consistent with the proposed research by Devadas and Dhawan, in 2010, that there was existence barriers HIV-1 virus replication by heme oxygenase-1. However HO- 1 from their studies didnot come fromexposure to OHB but was induced by administration of hemin or lipopolysaccharide in the cultured of monocytes.It can be explained that in the treatment group, the levels of ROS ishigher than the control group as it gets exposure to ROS derived from HIV-1 viralreplication as well as from exposure to OHB, whereas in the control group ROSmolecules derived only from virus replication. However, the average levels of heme oxygenase-1 was higher in the treatment group. This suggests that exposureto OHB was able to induce heme oxygenase-1 as a response mechanism that actsas a cell adaptive anti-oxidants than as antiviral.

\section{Analysis the number of antigen p24 HIV-1}

The result showed that the treatment group had a number of viruses that weresignificantly lower than the control group. Biomolecular effects of hyperbaric oxygen exposure at therapeutic dose through increasing ROS molecules will activate NFKB as transcription factors which were caused the expression of genes that produce proteins were required in the cell adaptive response.In this condition, HO-1 acts more as an antioxidant than antiviral. The antigen test is a valid measurement to measure productivity of infection. The concentration of HIV-1 p24 antigens in the culture supernatant fluids can be observed after the $5^{\text {th }}$ day of viral infection (Yang et al., 2013).

\section{Conclusion}

Exposure with hyperbaric oxygen at 2.4 ATA and 100\% oxygen for 3x30 minutesfor 5 day in cultured of PBMCs infected HIV-1, was increased theadaptive response of cells by significantly decreased the number of antigenp24 HIV-1, but not in increased the expression of heme oxygenase-1.The decreased number of HIV-1 p24 antigen in the treatment group showedthat cellsadaptive response result from activation of thetranscription factor to produce innate antiviral and inhibit viral replication.

Conflict of Interest: Authors declare no conflicts of interest associated with this manuscript. $\mathrm{K}$ and $\mathrm{N}$ conceived and supervised the study; RB, S and SQK designed experiments; RB and SQK performed experiments; RB and SQK collected samples and clinical information; RB and SQK analysed data; RB wrote the manuscript; RB, K and SQK made manuscript revisions.

Acknowledgments: We acknowledge the support of Sub division of HIV Laboratory Institute of Tropical Disease, Airlangga University and Lembaga Kesehatan Angkatan Laut (LAKESLA) Surabaya Indonesia. This work was funded by Indonesian government (DIKTI - Hibah Bersaing Simlitabmas). 


\section{References}

1. Abdalla, M.Y., Britigan, BE., Wen F., Icardi, M., McCormick ML., LaBrecque DL., Voigt M., Brown KE., Schmidt WN., (2004) Down-regulation of hemeoxygenase-1 by hepatitis $C$ virus infection in vivo and by the in vitro expression of hepatitis C core protein. J Infect Dis 190, 1109-1118.

2. Devadas, K., Dhawan, S. (2006) Hemin activation ameliorates HIV-1 infection viaheme oxygenase-1 induction. J. Immunol. 176, 4252-7.

3. Devadas, K., Hewlett, I.K., Dhawan, S. (2010) Lipopolysaccharide suppressesHIV-1 replication in human monocytes by protein kinase C-dependent hemeoxygenase-1 induction. J. Leukoc. Biol. 87, 915-924.

4. Gill, A.J., Kovacsics C., Vance P., Collman R.,Kolson D,(2015) Induction of Heme Oxygenase-1 Deficiency and Associated Glutamate Mediated Neurotoxicity is a Highly Conserved HIV Phenotype of Chronic Macrophage Infection That Is Resistant to Antiretroviral Therapy. J. Virol. 89, 10656-10667.

5. Rothfuss, A., Radermacher, P., Speit, G. (2001) Involvement of heme oxygenase-1(HO-1) in the adaptive protection of human lymphocytes after hyperbaric oxygen (HBO) treatment. Carcinogenesis 22, 1979-1985.

6. Simsek, K., Oter, S., Ay, H. (2011) Hyperbaric oxygen therapy and its mechanismsof action: implication of several molecular processes along with reactive species. J. Exp. Integr. Med. 1, 205-206.

7. Simsek, K., Sadir, S., Oter, S. (2015). The relation of hyperbaric oxygen withoxidative stress - reactive molecules in action. Oxid.Antioxid. Med. Sci. 4, 17.

8. Speit, G., Bonzheim, I. (2003) Genotoxic and protective effects of hyperbaricoxygen in A549 lung cells. Mutagenesis 18, 545-548.

9. Yang, H., Yorke E., Hancock G., Clutton G., Sande N, Angus B., Smyth R., Mak J., Dorrell L., (2013) Improved Quantification of HIV-1 infected CD4 T Cell Using an Optimized method Of Intracellular HIV-1 Gag p24 Antigen Detection. J. of Immun. Methods. 391, 174-78. 